Programa de Residência Pedagógica na Licenciatura em Informática: partilhando possibilidades

\title{
SALA DE AULA INVERTIDA E O ENSINO DE PROGRAMAÇÃO DE COMPUTADORES
}

\author{
Abdon Soares de Souza Júnior ${ }^{1}$, Daniel Aguiar da Silva Oliveira Carvalho²
}

\section{PALAVRAS-CHAVE}

Ensino de Programação;

Metodologias Ativas;

Sala de Aula Invertida.

\section{RESUMO}

O Projeto Institucional de Residência Pedagógica do IFRN demonstra-se de grande importância por possibilitar ao estudante de Licenciatura em Informática o fortalecimento de sua formação acadêmica por meio da imersão no ambiente escolar, promovendo a vivência e experimentação de situações concretas do dia-a-dia da escola e da sala de aula, estimulando a reflexão sobre a relação teoria e prática, e dando início a qualificação profissional do futuro docente. O presente capítulo visa relatar a experiência de um bolsista residente do Programa de Residência Pedagógica, no ensino de Programação de Computadores, no Curso Técnico de Nível Médio Integrado em Informática, do IFRN, Campus Ipanguaçu. O residente teve como desafio aplicar as teorias estudadas por ele no curso de Licenciatura em Informática e desenvolver estratégias metodológicas eficazes para o ensino de programação de computadores. $O$ processo de ensino e aprendizagem da programação de computadores é rico em desafios e dificuldades, tais como a assimilação e aplicação de alguns conceitos por parte dos alunos, os elevados níveis de reprovação e evasão, principalmente em disciplinas nas quais são ensinados conceitos básicos de programação, em qualquer grau ou sistema de ensino. Trata-se, portanto, de um problema universal que tem sido objeto de estudo de diversas pesquisas, resultando no surgimento de variados métodos e sistemas, sem que, contudo, tenha-se chegado a um resultado significativamente positivo e, ao mesmo tempo, abrangente. Na busca por métodos de ensino e aprendizagem mais adequados ao nível cognitivo do aluno e aos seus estilos preferenciais de aprendizado, o residente e o docente da disciplina Programação Estruturada e Orientada a Objetos (PEOO), utilizaram, juntamente com as metodologias mais tradicionais centradas na atividade de resolução de problemas e construção de fluxogramas, abordagens híbridas de ensino, especialmente a sala de aula invertida (SAI) ou flipped classroom, bem como o uso de mapas conceituais.

1 Graduando do Curso Superior de Licenciatura em Informática no Instituto Federal de Educação, Ciência e Tecnologia do Rio Grande do Norte (IFRN), Campus Ipanguaçu. E-mail: souzabdon @gmail.com

2 Professor Efetivo do Instituto Federal de Educação, Ciência e Tecnologia do Rio Grande do Norte (IFRN) - Campus Ipanguaçu. Formado em Tecnologia em Análise e Desenvolvimento de Sistemas (IFRN) com Mestrado em Sistemas e Computação pela Universidade Federal do Rio Grande do Norte (UFRN). E-mail: daniel.aguiar@ifrn.edu.br 


\section{Abdon Souza \& Daniel Carvalho}

\section{INTRODUÇÃO}

O Programa de Residência Pedagógica é uma das ações que integram a Política Nacional de Formação de Professores e tem por objetivo induzir o aperfeiçoamento da formação prática nos cursos de licenciatura, promovendo a imersão do licenciando na escola de educação básica, a partir da segunda metade de seu curso. A inserção de projetos educacionais no interior das escolas públicas, dinamizam o ambiente de ensino-aprendizagem e torna possível uma maior interação do residente com a realidade da educação básica (Edital CAPES nº 06/2018 - Programa de Residência Pedagógica).

São abordagens e ações obrigatórias da residência pedagógica a apropriação analítica e crítica da Base Nacional Comum Curricular (BNCC) nos seus princípios e fundamentos que orientam o ensino desde a educação básica, devendo priorizar o domínio do conhecimento pedagógico do conteúdo curricular ou o conhecimento das ações pedagógicas que permitem transformar os objetos de estudo em objetos de ensino e aprendizagem. Deverá priorizar também atividades que envolvam as competências, os conteúdos das áreas e dos componentes, unidades temáticas e objetos de estudo previstos na BNCC, criando e executando sequências didáticas, planos de aula, avaliações e outras ações pedagógicas de ensino e aprendizagem. (CAPES, 2018, Anexo III)

De acordo com o Projeto Institucional de Residência Pedagógica do IFRN, registrado na Plataforma Freire, o Programa de Residência Pedagógica demonstra-se de grande importância por possibilitar ao estudante de Licenciatura, o fortalecimento de sua formação acadêmica por meio da imersão no ambiente escolar, promovendo a vivência e experimentação de situações concretas do dia-a-dia da escola e da sala de aula, estimulando a reflexão sobre a relação teoria e prática, e dando início a qualificação profissional do futuro docente.

Vivenciar a prática do professor de programação de computadores e como se desenvolve a aprendizagem dos alunos, é essencial para que o licenciando em informática possa minimizar as dificuldades que enfrentará nos anos iniciais da docência.

Apesar de vivermos em uma sociedade informatizada, nota-se o frequente insucesso nas disciplinas de programação de computadores em capacitar os alunos a implementarem a solução de um determinado problema através do uso de alguma linguagem de programação, mesmo quando o problema dado apresenta um baixo grau de complexidade (GOMES, HENRIQUES e MENDES, 2008). Percebe-se atualmente, que para se conseguir o comprometimento e motivação dos alunos, é preciso inovar, inserir tecnologia no plano de aula e colocar os meios tecnológicos mais usados pelos estudantes a favor do conteúdo proposto. É neste ponto que a sala de aula invertida pode se tornar uma alternativa relevante.

No modelo de sala de aula tradicional, o professor explica o conteúdo no quadro em uma aula expositiva para que depois os alunos façam, sozinhos, a lição de casa. Já no modelo de sala de aula invertida acontece a inversão da lógica do modelo tradicional: primeiro o aluno faz a internalização dos conceitos essenciais do conteúdo, fora da sala de aula, e depois, juntamente com a turma, na sala de aula, e 


\section{Abdon Souza \& Daniel Carvalho}

com a ajuda e orientação do professor, discute os conhecimentos adquiridos e tira possíveis dúvidas sobre o conteúdo.

A proposta deste capítulo é apresentar a experiência vivida por um aluno de um curso de Licenciatura em Informática, no Programa de Residência Pedagógica. Com base nessa proposta, pode-se definir o objetivo deste projeto como sendo relatar as experiências do residente no programa, mais especificamente no que se refere as dificuldades e desafios do ensino de programação de computadores e, a partir dessas dificuldades e desafios, a utilização do modelo de sala de aula invertida como proposta pedagógica.

Este documento organiza-se da seguinte forma: a seção 1 contextualiza e apresenta os objetivos do trabalho. Em seguida, na seção 2, são abordadas as dificuldades e desafios do ensino/aprendizagem de programação de computadores por meio de fundamentação teórica e das experiências vividas pelo residente no Programa de Residência Pedagógica. Relatos das experiências referentes a utilização do modelo de sala de aula invertida no ensino de Programação de Computadores, no Curso Técnico de Nível Médio Integrado em Informática, do IFRN, Campus Ipanguaçu, são descritos na seção 3. Por fim, na seção 4, serão apresentadas as considerações finais e trabalhos futuros.

\section{O ENSINO E APRENDIZAGEM DE PROGRAMAÇÃO DE COMPUTADORES E SUAS DIFICULDADES}

A programação de computadores é uma atividade direcionada à solução de problemas e, nesse sentido, está relacionada com uma gama variada de outras atividades como especificação, projeto, validação, modelagem e estruturação de programas e dados, utilizando-se, como ferramentas, as linguagens de programação. A atividade de programação é uma ciência que envolve um conjunto de formalismos, de princípios como abstração e encapsulamento, de técnicas como modularização e programação estruturada, que visam a produção de softwares bem estruturados e confiáveis. O estudo de programação não se restringe ao estudo de linguagem de programação, pois este deve ser precedido do estudo dos principais paradigmas de programação, especialmente a programação imperativa, a funcional, a baseada em lógica e a orientada a objetos (BRASIL, 2001).

Berssanete (2016) afirma que no Brasil, o ensino de programação ocorre principalmente nos cursos superiores das áreas de computação e informática, nos cursos técnicos profissionalizantes subsequentes e na modalidade técnica integrada ao ensino médio que está sendo abordada nesse trabalho. De modo geral, o início dos processos de ensino e de aprendizagem de programação de computadores ocorre por meio de um conjunto de disciplinas introdutórias identificadas como Lógica de Programação, Algoritmos, Programação Estruturada e Orientada a Objetos, entre outras. Estas disciplinas objetivam fornecer aos alunos conceitos básicos de programação e um conjunto de comandos com os quais poderão solucionar problemas variados e implementá-los num ambiente computacional.

Alguns aspectos fundamentais da parte introdutória do ensino de programação são: como resolver problemas; como descrever uma solução 


\section{Abdon Souza \& Daniel Carvalho}

algorítmica e como verificar se um algoritmo está correto (GOMES; HENRIQUES; MENDES, 2008). Geralmente, o conteúdo abordado nas disciplinas introdutórias de programação contempla a descrição dos passos necessários para se solucionar um problema; entradas e saídas de dados; constantes e variáveis; tipos primitivos de dados; instrução de atribuição; operadores aritméticos, relacionais e lógicos; estruturas simples de controle de fluxo, decisão e repetição; orientação a objetos (BERSSANETTE, 2016). Alguns professores optam por evitar o contato dos alunos com uma linguagem de programação nessa fase introdutória do ensino de programação.

A literatura apresenta variadas justificativas para as dificuldades inerentes ao ensino e aprendizagem de programação. Dijkstra (1989) e Perkins (1988) argumentam que a aprendizagem de programação é um processo lento e gradual que requer um treino intensivo em resolução de problemas, envolvendo competências de diversas áreas para se obter um pequeno retorno.

Todavia, Júnior e Rapkiewicz (2004, 2005) entendem que não há nada inerentemente difícil ao conteúdo de programação, mas existem alunos que não possuem as aptidões necessárias para programar, especialmente no que se refere a resolução de problemas e a matemática.

Jenkins (2002) aponta diversas causas do insucesso generalizado em disciplinas de programação, tais como: o baixo nível de abstração dos alunos, a inadequação dos métodos pedagógicos e os estilos de aprendizagem dos alunos. Entende ainda que a maioria das linguagens de programação utilizadas nas disciplinas introdutórias apresentam sintaxes complexas e inadequadas para quem está aprendendo a programar.

Já para Bini e Koscianski (2009), uma razão para a dificuldade de assimilação das abstrações presentes no processo de aprendizagem, foco dos estudos de Pereira Júnior e Rapkjewikz (2004), é a falta de comprovação prática com feedback imediato e fiel proporcionado pela implementação direta no computador.

Outras dificuldades que podem ser identificadas a partir do levantamento na literatura: por parte dos alunos, interpretar do problema, interpretar algum tipo de representação, interpretar enunciados (FALKEMBACH et al, 2003); aplicar suas habilidades prévias, causando fonte de medo e frustação (Chaves de Castro et al, 2003).

Por outro lado, considerando os professores, enumeram-se dificuldades de identificar no aluno os pré-requisitos necessários para o desenvolvimento das competências de construção de algoritmos e programação, como o domínio de habilidades matemáticas prévias ou pelo menos integradas (HENDERSON, 1987; KOLIVER, DORNELES e CASA, 2004); e dificuldades para trabalhar a capacidade do aluno compreender a abstração envolvida com toda simbologia utilizada, tanto na busca de possíveis soluções quanto na escolha das estruturas de dados (Nobre e Menezes 2002; Rodrigues, 2002; Schultz, 2003).

Um dos pontos de divergência encontrados na literatura é quanto a necessidade ou não de se definir um paradigma de programação para estruturar as soluções de problemas. Discute-se a forma de representação da solução com suas ferramentas de apoio e se as próprias linguagens de programação, quando utilizadas, devem ou não estar relacionadas a algum paradigma. Segundo o relatório da força 


\section{Abdon Souza \& Daniel Carvalho}

tarefa da IEEE e ACM (2001), o estudo de algoritmos deve fornecer o discernimento da natureza intrínseca do problema, além de técnicas de solução independentes de qualquer paradigma, linguagem de programação ou hardware. Esta também é a visão de autores como Henderson (1986) e Koliver, Dorneles e Casa (2004). Já autores como Chaves de Castro et al (2003), afirmam que alguns paradigmas, como o funcional, podem facilitar o processo de ensino/aprendizagem de programação; outros defendem o paradigma imperativo, preferivelmente orientado a objeto para Baeza-Yates (1995), enquanto Delgado et al (2004) dá preferência ao estruturado clássico.

Segundo Gries (1974), a programação seria possivelmente uma das únicas disciplinas na qual se tenta ensinar métodos de resolução de problemas gerais, visto que em outras como filosofia, matemática e física, o aluno aprende e aplica conceitos para resolver problemas específicos, não sendo capaz de generalizá-los.

De acordo com Gomes, Henriques e Mendes (2008), a programação de computadores possui uma natureza específica que, diferentemente da maioria das disciplinas, resulta no ensino de muitos conceitos dinâmicos que é, geralmente, apresentado através de materiais de natureza estática (explicações verbais, uso de projeções, desenhos no quadro, diagramas, textos, entre outros) que não promovem a plena compreensão da dinâmica envolvida. Na visão desses autores, a estrutura curricular das disciplinas de programação está virada ao contrário, pois é prática comum se começar a ensinar uma linguagem de programação antes que os alunos percebem qual a finalidade e utilidade de se aprender a programar, quando, a preocupação principal deveria ser, antes de tudo, o desenvolvimento da capacidade de resolução de problemas, apresentando-se a linguagem de programação simplesmente como um meio para expressar o algoritmo ou estratégia de resolução.

Ainda de acordo com Gomes, Henriques e Mendes (2008), os alunos estão habituados a disciplinas nas quais é possível se obter sucesso por meio de métodos de estudo baseados em leituras sucessivas, memorização de fórmulas e uma certa mecanização. No entanto, a programação exige uma prática intensiva, uma compreensão mais aprofundada que permita o domínio dos assuntos, bastante reflexão, além de bons conhecimentos matemáticos, persistência na resolução de problemas e um intenso trabalho extra sala de aula. $\mathrm{O}$ conhecimento adquirido na busca por compreender, implementar e resolver problemas complexos permite o desenvolvimento de estruturas cognitivas importantíssimas para o domínio da programação.

Como pode-se perceber, existem diversas opiniões e por vezes divergentes no que diz respeito as causas das dificuldades do ensino e aprendizagem de programação, em função das quais têm surgido diversos métodos e ferramentas com o objetivo de minimizar essas dificuldades. Contudo, apesar dos resultados positivos alcançados pela utilização desses métodos e ferramentas no desempenho de alguns alunos, as taxas de repetência, desistência e evasão em disciplinas de programação continuam elevadas (GOMES; HENRIQUES; MENDES, 2008).

Como forma de minimizar as dificuldades dos processos de ensino e aprendizagem, Moran (2017) destaca que num mundo conectado e digital, as metodologias ativas, que são estratégias de ensino centradas na participação ativa dos alunos na construção do processo de aprendizagem de forma flexível, 


\section{Abdon Souza \& Daniel Carvalho}

interligada, híbrida; se expressam por meio do ensino híbrido, com muitas possíveis combinações. A junção de metodologias ativas com modelos flexíveis e híbridos é uma alternativa poderosa para desenvolver estratégias interessantes de ensinar e aprender.

Em um questionário de caracterização da turma aplicado pelo residente na turma INFO2M ( $2^{\circ}$ ano, matutino), disciplina Programação Estruturada e Orientada a Objetos (PEOO) do Curso Técnico de Nível Médio Integrado em Informática, do IFRN - Campus Ipanguaçu, observou-se as seguintes respostas de 21 alunos às perguntas de um quadro deste questionário:

Tabela 1 - Perguntas relacionadas a sala de aula

\begin{tabular}{|c|c|c|c|}
\hline $\begin{array}{c}\text { EM SALA DE AULA: } \\
\text { (Marque com X apenas UMA OPÇÃO em cada linha) }\end{array}$ & Nunca & $\begin{array}{l}\text { Algumas } \\
\text { Vezes }\end{array}$ & Sempre \\
\hline Acompanho o conteúdo exposto pelo professor. & 1 & 10 & 10 \\
\hline $\begin{array}{l}\text { Copio e faço anotações no meu caderno sobre os conteúdos } \\
\text { ministrados. }\end{array}$ & 11 & 10 & - \\
\hline Fico completamente perdido durante as explicações do professor. & 5 & 15 & 1 \\
\hline $\begin{array}{l}\text { Me distraio facilmente com (celular, conversas, etc.) durante as } \\
\text { aulas. }\end{array}$ & 2 & 13 & 6 \\
\hline $\begin{array}{l}\text { Me sinto à vontade para fazer perguntas e tirar dúvidas durante } \\
\text { as aulas. }\end{array}$ & 6 & 8 & 7 \\
\hline $\begin{array}{c}\text { O professor explica o conteúdo de forma clara, para que todos } \\
\text { entendam. }\end{array}$ & - & 15 & 6 \\
\hline Pesquiso na internet conteúdos vistos durante as aulas. & 1 & 16 & 4 \\
\hline Realizo todas as atividades que o professor propõe. & 2 & 6 & 13 \\
\hline Discuto a avaliação realizada pelo professor. & 10 & 7 & 4 \\
\hline Costumo pesquisar o conteúdo antes da exposição do professor. & 11 & 10 & - \\
\hline Faço vários exercícios em casa até me familiarizar com o conteúdo. & 8 & 12 & 1 \\
\hline Refaço questões que erro em exercícios e avaliações. & 10 & 10 & 1 \\
\hline
\end{tabular}

Fonte: Elaboração própria (2019)

Observa-se que: 47,6\% dos alunos sempre estão acompanhando a disciplina; $71,4 \%$ ficam completamente perdidos durante as explicações do professor, algumas vezes; $61,9 \%$ se distraem facilmente com (celular, conversas, etc.) durante as aulas, algumas vezes; $33,3 \%$ dos alunos nunca se sente à vontade para fazer perguntas e 


\section{Abdon Souza \& Daniel Carvalho}

tirar dúvidas durante as aulas; $71,4 \%$ dos alunos acha que, somente algumas vezes, o professor explica o conteúdo de forma clara, para que todos entendam; 76,2\% pesquisa na internet conteúdos vistos durante as aulas, algumas vezes; $61,9 \%$ realiza todas as atividades que o professor propõe; $47,6 \%$ dos alunos nunca discute sobre a avaliação realizada pelo professor; $52,4 \%$ dos alunos não costuma pesquisar o conteúdo antes da exposição do professor; $38,1 \%$ dos alunos nunca faz exercícios em casa até se familiarizar com o conteúdo e 57,1\% faz algumas vezes; $47,6 \%$ dos alunos nunca refaz as questões que erraram em exercícios e avaliações e o mesmo percentual refaz apenas algumas vezes.

Outras 03 perguntas do questionário referem-se as experiências, o comportamento e a rotina dos alunos e podem ser relacionadas com suas dificuldades no aprendizado da disciplina Programação Estruturada e Orientada a Objetos (PEOO). Ao se analisar os resultados conjuntamente, observa-se a relação direta de proporcionalidade. $42,9 \%$, um pouco menos da metade dos alunos que responderam o questionário, não disponibilizam nenhum tempo, fora da sala de aula, para o estudo da disciplina PEOO; a grande maioria, 95,2\%, não tiram dúvidas sobre a disciplina com algum tutor/monitor; do total dos alunos que sentem dificuldade no aprendizado da disciplina PEOO, 47,6\% destaca como causa dessa dificuldade, a falta de uma base mais sólida em conteúdos vistos anteriormente como Fundamentos de Lógica e Algoritmos, por exemplo e, o mesmo percentual de 47,6\%, destaca como causa da dificuldade, a forma (metodologia/didática) como é dado o conteúdo da disciplina.

A partir da análise dessas questões, percebe-se que há uma notória dificuldade no ensino e aprendizagem da disciplina PEOO, fato este que não surpreende a ninguém, visto que essa dificuldade no ensino de programação e a busca dos docentes por novas e variadas metodologias que auxiliem e facilitem esse processo, não ocorre somente no IFRN, ocorre em todo Brasil e no mundo. Existem diversos estudos e experiências sobre o assunto, mas o que mais se propaga e se defende atualmente é que o ensino de programação se inicie logo no Ensino Fundamental.

Além das dificuldades descritas na literatura e citadas aqui e também das dificuldades experimentada pelo residente durante sua regência, tem que ser levado em consideração o fato da residência ser desenvolvida em um curso técnico de nível médio integrado onde, além da disciplina de programação, os alunos tinham que dividir seus horários de estudo com muitas e diversas disciplinas. Pensando nisso, o residente teve a ideia de combinar tecnologias educacionais e ferramentas de suporte com metodologias ativas, como o método da sala de aula invertida, visando encontrar uma solução que atendesse as demandas, hábitos, comportamentos e a realidade desses alunos das disciplinas de programação.

\section{A SALA DE AULA INVERTIDA NO ENSINO DE PROGRAMAÇÃO DE COMPUTADORES}

A maneira como professores ensinam e como os alunos aprendem é um assunto amplamente discutido na literatura. À saber, Lage et al. (2000) apontam que as incompatibilidades entre o estilo de ensino do professor e o estilo de 


\section{Abdon Souza \& Daniel Carvalho}

aprendizagem do aluno podem resultar em estudantes menos interessados no assunto. Estes autores também afirmam que é preciso considerar a utilização de metodologias de ensino variadas com o objetivo de alcançar um engajamento ativo dos alunos. Powell (2003) observa que na resolução de problemas em sala de aula, tanto os alunos como o professor, estarão disponíveis para uma interação mais significativa. Entretanto, esta atividade também é criticada por consumir muito tempo, restando pouco tempo para a aula expositiva do professor. Barreto (2014) afirma que as exposições de conteúdos gravados em vídeos podem ser vistas em qualquer lugar e quantas vezes forem necessárias, deixando tempo para atividades em grupos na sala de aula.

Diante desta problemática, o Ensino Híbrido (blended learning) surge como uma solução. Este é uma metodologia considerada inovadora, que utiliza tecnologias no processo de ensino aprendizagem, promovendo uma mistura entre o ensino presencial e propostas de ensino online, em modelos que mesclam momentos em que o aluno estuda sozinho, por meio das tecnologias digitais, com outros em que a aprendizagem acontece de forma presencial, valorizando a interação entre pares e entre aluno e professor.

Como afirma Hoffmann (2016), o Ensino Híbrido não proporciona uma única maneira de ensinar e aprender, porque é um processo contínuo que ocorre de diferentes formas e em diferentes espaços. Adicionalmente, segundo Camillo et al (2018), para que este método de ensino ocorra é necessário que a tecnologia, o papel do educador, a gestão, a avaliação, bem como a autonomia do educando, a cultura escolar e o espaço estejam em sincronia.

O Ensino Híbrido dispõe de quatro modelos que podem ser utilizados na educação: Rotação, Flex, A La Carte e Virtual Enriquecido. No modelo de Rotação os alunos revezam entre modalidades de ensino, em roteiro fixo pré-definido ou a critério do professor, sendo que em pelo menos uma destas modalidades, deve-se adotar a do ensino online. $\mathrm{O}$ modelo de Rotação se divide em quatro submodelos: Rotação por Estações, Laboratório Rotacional, Sala de Aula Invertida e Rotação Individual, conforme Quadro 2. É importante ressaltar que, para este trabalho, utilizamos a Sala de Aula Invertida (SAI).

Quadro 2 - Submodelos do Modelo de Rotação de Ensino Híbrido

\begin{tabular}{|l|l|}
\hline \multicolumn{1}{|c|}{ Modelo } & \multicolumn{1}{c|}{ Descrição } \\
\hline Rotação por Estações & $\begin{array}{l}\text { Também chamado de Rotação de Turmas ou } \\
\text { Rotação em Classe - submodelo no qual os alunos } \\
\text { revezam dentro do ambiente de uma sala de aula. }\end{array}$ \\
\hline $\begin{array}{l}\text { Laboratório } \\
\text { Rotacional }\end{array}$ & $\begin{array}{l}\text { Submodelo no qual a rotação acorre entre a sala } \\
\text { de aula e um laboratório de informática para o } \\
\text { ensino online. }\end{array}$ \\
\hline Sala de Aula Invertida & $\begin{array}{l}\text { Submodelo no qual a rotação acontece entre a } \\
\text { prática com supervisão presencial do professor na } \\
\text { escola e a residência do aluno ou outra localidade } \\
\text { fora da escola para aplicação do conteúdo e lições } \\
\text { online. }\end{array}$ \\
\hline Rotação Individual & Submodelo que difere dos outros porque, em \\
\hline
\end{tabular}




\begin{tabular}{|l|l|}
\hline essência, cada aluno tem um roteiro \\
individualizado e, não necessariamente, participa \\
de todas as estações ou modalidades disponíveis. \\
É o submodelo mais disruptivo do Modelo de \\
Rotação e o que mais utiliza o ensino online.
\end{tabular}

Fonte: Christensen, Horn e Staker (2013) adaptado pelo autor

De acordo com Bergman e Sams (2012) e Pierce e Fox (2012), a sala de aula invertida é uma abordagem híbrida de ensino descrita pelo educador americano Salman Khan e desenvolvida em 2007 pelos professores de Química do Ensino Médio Jonathan Bergmann e Aron Sams que, preocupados em solucionar o problema de alunos que também eram atletas e, por isso, se ausentavam frequentemente nas aulas presenciais, começaram a gravar e disponibilizar na web vídeos de suas aulas, transformando-as em ambientes de discussão aberta e aprendizagem ativa, guiadas pelo estudo prévio de seus alunos. Observa-se nessa abordagem a presença de três elementos pedagógicos: o uso de tecnologias digitais, a participação ativa do estudante em classe e o estudo prévio. Destaca-se também que o papel do professor é imprescindível. Este continua sendo o principal responsável para guiar os alunos sobre como compreender as novas informações, como também para indicar e aplicar os conteúdos (WILSON, 2013).

Na SAI, o professor indica o conteúdo antes mesmo da aula, para que os alunos já entrem em contato com o tema, em casa ou outro lugar de sua preferência, por meio de materiais digitais como vídeo aulas, tutoriais, apresentações, podcasts, entre outros. Após o estudo individual, os alunos, em sala de aula, tiram dúvidas com o professor, debatem com os colegas, podem trazer assuntos complementares e desenvolvem projetos e atividades em grupo, orientados pelo professor. Em casa, o aluno pode escolher a forma e o tempo para acessar o conteúdo, como a ordem de acessar os materiais, revê-los quando sentir dificuldade de compreensão e fazer pesquisas adjacentes. Na sala de aula presencial, a turma ganha tempo para explorar um conteúdo em profundidade e até mesmo produzir novos conhecimentos a partir do conhecimento adquirido e da interação entre os alunos e entre alunos e professor (SASSAKI, 2016).

Num mundo em que a tecnologia permeia o contexto diário das pessoas, sendo praticamente uma exigência dos dias atuais, a sala de aula invertida pode motivar os alunos a se tornarem mais autônomos, desenvolverem novas habilidades e serem sujeitos ativos de sua própria aprendizagem. Os docentes também se motivam para desenvolverem suas próprias vídeo-aulas para disponibilizá-las aos alunos (SASSAKI, 2016).

Entretanto, experiências como a de Suhr (2016), apontam que a falta de uma cultura de comprometimento dos educandos é um dos principais desafios para uma adoção bem-sucedida do modelo SAI. Outros autores, como Camillo et al (2018), destacam também como pontos negativos: a autonomia que o aluno precisa ter, a responsabilidade de estudar em casa, assistir as vídeo aulas, pesquisar material extra na internet para complementar os estudos, entre outros. Isso demanda por parte do aluno bastante consciência, organização, dedicação e disciplina para alcançar seus objetivos. Ou seja, apesar do método ser bem flexível e adaptável, nem todos os 


\section{Abdon Souza \& Daniel Carvalho}

alunos vão se adaptar ou estar maduros o suficiente para serem responsáveis pela sua aprendizagem e pelo seu sucesso.

Um questionário de caracterização aplicado na turma do segundo ano curso técnico integrado em informática buscava avaliar o grau de satisfação dos alunos quanto ao uso da Sala de Aula Invertida na disciplina de Programação Estruturada e Orientada a Objetos (PEOO) cursada no ano letivo 2018. Do total de respondentes, $33,3 \%$ indicaram que estavam satisfeitos ou muito satisfeitos; $28,6 \%$ que eram indiferentes e $38,1 \%$ que estavam insatisfeitos. Considerando os resultados, pode-se concluir que os $38,1 \%$ de alunos insatisfeitos e os $28,6 \%$ de alunos indiferentes ao método dever-se, possivelmente, ao fato de ser uma novidade a qual os alunos ainda não se familiarizaram, uma resistência natural a mudanças, falta de costume a ter um acesso prévio ao conteúdo a ser abordado em sala de aula o que corrobora com a alguns dos pontos destacados por Suhr (2016) e Camillo et al. (2018).

Atualmente, a Sala de Aula Invertida continua sendo utilizado, agora na turma de PEOO (ano letivo 2019) e também na turma do primeiro ano da disciplina Fundamentos de Lógica e Algoritmos. Novas adaptações e possibilidades como o uso em conjunto de dinâmicas em grupo (gincana baseada na modalidade de Ensino Híbrido "Rotação por Estações", para resolução de questões de uma lista de exercícios de revisão) e acesso prévio ao conteúdo e a atividades por meio de programas e aplicativos como Urionlinejudje, Code.org, Scratch e Lightbot.

Entre os principais desafios encontrados para o desenvolvimento dessa abordagem metodológica estavam a pouca familiaridade e o reduzido conhecimento prático, por parte do residente e do professor, na utilização da SAI em situação real de ensino-aprendizagem. É fato que menos de um ano de exposição aos princípios da Sala de Aula Invertida não foi suficiente para consolidar essa metodologia de ensino que exige um repensar na postura, tanto dos professores como dos alunos. Contudo, a experiência foi relevante e continua a ser utilizada, agora de outras formas mais enriquecidas e com as devidas adaptações, em outras turmas do ensino de programação e por outros professores do IFRN, Campus Ipanguaçu.

\section{CONSIDERAÇÕES FINAIS}

Ao ingressar no programa, o residente se vê diante do papel de um docente em formação. O programa o faz refletir sobre o seu comportamento como aluno, sobre o papel dos seus professores do passado e do presente. O programa põe para pensar sobre a formação como pessoa, como cidadão, como profissional e sobre o seu papel como futuro profissional docente.

Levando em consideração essas perspectivas, essas experiências vividas no programa vão aperfeiçoando o residente como um professor mais reflexivo, que buscará cotidianamente aprimorar a sua formação docente e o seu processo de ensino e de aprendizagem.

O Programa de Residência Pedagógica incentiva e estimula os futuros docentes que optaram pela licenciatura a aplicarem as teorias aprendidas ao longo do curso, transformando-as e aproximando-as da realidade vivida em sala de aula. $\mathrm{O}$ programa busca não somente a melhor formação docente, mas também fomenta uma 


\section{Abdon Souza \& Daniel Carvalho}

rica parceria entre as Instituições de Ensino Superior (IES) e as escolas de educação básica, proporcionando benefícios para todo o sistema de ensino.

As metodologias tradicionalmente utilizadas para o ensino e aprendizagem de programação, principalmente de seus conceitos mais básicos, na maioria das vezes não se revelam suficientes em conseguir que os alunos desenvolvam suas capacidades de conceber programas capazes de resolver problemas reais simples. É fundamental que professores e instituições de ensino sejam persistentes na busca de inovações metodológicas, para o ensino de programação e de outras disciplinas, que se adequem ao contexto do ambiente escolar, aos níveis cognitivos dos alunos, bem como aos seus estilos preferenciais de aprendizagem.

A experiência do residente com a utilização do método de sala de aula invertida no ensino de programação de computadores demonstrou-se relevante pelo fato de ter sido o ponta pé inicial na busca por metodologias educacionais inovadoras, combinadas com o uso de ferramentas tecnológicas.

Destaca-se a necessidade de se aperfeiçoar cotidianamente e de se buscar sempre a melhoria do processo de ensino e aprendizagem, adaptando as novas estratégias metodológicas e os avanços tecnológicos como os dispositivos móveis, por exemplo, aos diferentes estilos de aprendizagem dos alunos.

Com o uso cada vez mais massivo dos smartphones, o desenvolvimento de estratégias de aprendizagem apropriadas para o contexto mobile e a experimentação do mobile learning ou m-learning, apresentam-se como excelentes possibilidades para trabalhos futuros.

Apesar do crescente interesse pelo método da sala de aula invertida e do amplo número de artigos sobre o tema na literatura internacional, no Brasil, pelo que se pôde observar, a literatura ainda é limitada. Essa incipiência de produções é ainda maior com relação às experiências sobre o processo de desenvolvimento da SAI no contexto escolar. Essas constatações devem subsidiar críticas e reflexões futuras.

\section{REFERÊNCIAS}

BARRETO, J. A Case Study for Teaching Quantitative Biochemical Buffer Problems Using Group Work and "Khan Style" Videos. Journal of College Science Teaching. v. 44, n. 1, p. 34-39, 2014.

BRASIL. Ministério da Educação. Secretaria de Educação Superior. Diretrizes Curriculares de Cursos da área de Computação e Informática. Brasília: MEC/SESU, 2001.

BAEZA-YATES, R. A. (1995). Teaching Algorithms. SIGACT News, 26, 4, 51-59.

BERGMAN, J.; SAMS, A. Flipped learning: gateway to student engagement. Atlanta (EUA): ISTE, 2014.

BERGMANN, J.; SAMS, A. Flip your students learning. Technology-Rich Learning, v.70, n.6, p. 1620, March 2013. 
BERGMANN, J.; SAMS, A. Flip Your Classroom: reach every student in every class every day. Eugene, Oregon: Iste, 2012.

BERSSANETTE, João Henrique. Ensino de programação de computadores: uma proposta de abordagem prática baseada em Ausubel. 2016. 144f. Dissertação (Mestrado em Ensino de Ciências e Tecnologia) - Universidade Tecnológica Federal do Paraná. Ponta Grossa, 2016.

BINI, E. M.; Koscianski, A. (2009). O Ensino de Programação de Computadores em um Ambiente Criativo e Motivador. Anais do VII ENPEC 2009, Brasil.

CAMILLO, Cíntia Morales; VARGAS, Manuela Eliza Gularte; MEDEIROS, Liziany Muller. Ensino Híbrido: A Sala de Aula Invertida como Possibilidade de Ensino e Aprendizagem. In: $3^{\mathrm{o}}$ Encontro de Licenciaturas e Pesquisas em Educação (ELPED'2018). Rio Verde, GO, Brasil.

CAPES. Edital 6: Chamada Pública para apresentação de propostas no âmbito do Programa de Residência Pedagógica. 2018. Brasília: Ministério da Educação, 2018.

CHAVES DE CASTRO, T.; CASTRO JÚNIOR, A.; MENEZES, C.; BOERES, M.; RAUBER, M. (2003). Utilizando Programação Funcional em Disciplinas Introdutórias de Computação. Anais do WEI 2003, Brasil.

CHRISTENSEN, C. M.; HORN, M. B.; STAKER, H. Ensino Híbrido: uma Inovação Disruptiva? Uma introdução à teoria dos híbridos. [S. 1: s. n], 2013. Traduzido para o Português por Fundação Lemann e Instituto Península. Disponível em: www.christenseninstitute.org. Acesso em: 27 de set. de 2019.

DATIG, I.; RUSWICK, C. Four Quick Flips: Activities for the Information Literacy Classroom. College \& Research Libraries News, v. 74, n. 5, p. 249-251, 257, 2013. Disponível em: <http://crln.acrl.org/content/74/5/249.full\#sec->. Acesso em: 01 out. 2019.

DELGADO, C.; XEXEO; J. A. M.; SOUZA, I. F.; CAMPOS, M.; RAPKIEWICZ, C. E. (2004). Uma Abordagem Pedagógica para a Iniciação ao Estudo de Algoritmos. XII Workshop de Educação em Computação (WEI'2004). Salvador, BA, Brasil.

DIJKSTRA, Edsger W. (1989). On the Cruelty of Really Teaching Computing Science. In: Communications of ACM, Issue 12, (vol.32), 1398-1404. 
FALKEMBACH, G. A. M., AMORETTI, M. S. M., TAROUCO, L. R., VIERO, F. (2003). Aprendizagem de Algoritmos: Uso da Estratégia Ascendente de Resolução de Problemas. $8^{\circ}$ Taller Internacional de Software Educativo. Santiago, Chile.

GOMES, A.; HENRIQUES, J.; MENDES, A. J. (2008). Uma proposta para ajudar alunos com dificuldades na aprendizagem inicial de programação de computadores. In: Educação, Formação \& Tecnologias; vol.1(1), pp. 93- 103. Disponível em http:/ / eft.educom.pt. Acesso em 04 de outubro de 2019.

GOUWS, Lindsey Ann; BRADSHAW, Karen; WENTWORTH, Peter. Computational thinking in educational activities: an evaluation of the educational game lightbot. In: Proceedings of the 18th ACM conference on Innovation and technology in computer science education. ACM, 2013. p. 10-15.

GRIES, D. (1974). What should we teach in an introductory programming course? In: Proceed-ings of the fourth SIGCSE technical symposium on Computer Science education, ACM Press, pp. 81-89.

HENDERSON, P. (1987). Modern Introductory Computer Science. In: Proceedings of the Eighteenth SIGCSE Technical Symposium on Computer Science Education, ACM Press, pp. 183-190.

HENDERSON, P. B. (1986). Anatomy of an Introductory Computer Science Course. In: Proceedings of the Seventeenth SIGCSE Technical Symposium on Computer Science Education, ACM Press, pp. 257-264.

HOFFMANN, E. H. Ensino Híbrido no Ensino Fundamental: Possibilidades e Desafios. Disponível em:

<https://repositorio.ufsc.br/xmlui/bitstream/handle/123456789/168865/TCC_Hof fmannpdf >Acesso em: 26 de set. de 2019.

JENKINS, T. (2002). On the difficulty of learning to program. In: Proceedings of 3rd Annual LTSN_ICS Conference (Loughborough University, United Kingdom, August 27-29, 2002). The Higher Education Academy, p.53-58.

JÚNIOR, J. C. R. P.; RAPKIEWICZ, C. E. (2004). O Processo de Ensino e Aprendizagem de Algoritmos e Programação: Uma Visão Crítica da Literatura. In: III Workshop de Educação em Computação e Informática do estado de Minas Gerais (WEIMIG' 2004). Belo Horizonte, MG, Brasil.

JÚNIOR, J. C. R. P.; RAPKIEWICZ, C. E.; DELGADO, C.; XEXEO, J. A. M. (2005). Ensino de Algoritmos e Programação: Uma Experiência no Nível Médio. In: XIII Workshop de Educação em Computação (WEI'2005). São Leopoldo, RS, Brasil. 
KALELIOĞLU, Filiz. A new way of teaching programming skills to K-12 students: Code. org. Computers in Human Behavior, v. 52, p. 200-210, 2015.

KOLIVER, C.; DORNELES, R. V.; CASA, M. E. (2004). Das (muitas) dúvidas e (poucas) certezas do ensino de algoritmos. XII Workshop de Educação em Computação - WEI'2004. Salvador, BA, Brasil.

LAGE, M.J.; PLATT, G.J.; TREGLIA, M. Inverting the classroom: A gateway to creating an inclusive learning environment. Journal of Economic Education, Washington, v. 31, n. 1, p. 30, 2000.

MORAN, José. Metodologias ativas e modelos híbridos na educação. S. YAEGASHI et al. (Orgs). Novas Tecnologias Digitais: Reflexões sobre mediação, aprendizagem e desenvolvimento. Curitiba: CRV, p. 23-35, 2017.

NOBRE, I. A. M. N., MENEZES, C. S. (2002). Suporte à Cooperação em um Ambiente de Aprendizagem para Programação (SAmbA). XIII Simpósio Brasileiro de Informática na Educação - SBIE 2002. São Leopoldo, RS, Brasil.

PERKINS, D. N., SCHWARTZ, S. and SIMMONS, R.; (1988). Instructional Strategies for the Problems of Novice Programmers. In: R. E. Mayer (ed.), Teaching and Learning Computer Programming, p.153-178. Hillsdale, NJ: Lawrence Erlbaum Associates.

POWELL, K. Science education: Spare me the lecture. Nature, v. 425, p.234-236, 2003.

RESNICK, Mitchel et al. Scratch: Programação para todos. Comum. Acm, v. 52, n. 11, p. 60-67, 2009.

SASSAKI, Claudio, O que muda nas aulas quando se aplica a sala de aula invertida?. Blog Tecnologia na Educação, Nova Escola, 2016. Disponível em: < https:/ / novaescola.org.br/conteudo/3376/blog-tecnologia-educacao-comofunciona-sala-deaulainvertida?gclid=Cj0KCQjwrMHsBRCIARIsAFgSeI3Hla20Xq04oMCj0WQOwItR uQMpf_LC2kdf9Y2cOfI-UDf39o8YG7MaAi_1EALw_wcB\#>. Acesso em: 26 de set. de 2019.

SCHULTZ, M. R. O. (2003). Metodologias para Ensino de Lógica de Programação de Computadores. Monografia de Especialização. Universidade Federal de Santa Catarina (UFSC), Florianópolis, SC, Brasil. 
SUHR, I. R. F. Desafios no uso da sala de aula invertida no Ensino Superior. Transmutare, v. 1, n. 1, 2016.

TONIN, Neilor Avelino; BEZ, Jean Luca. Uri online judge: A new interactive learning approach. Computer Technology and Application, v. 4, n. 1, 2013.

WILSON, S.G. The Flipped Class: A Method to Address the Challenges of an Undergraduate Statistics Course. Teaching of Psychology, Philadelphia, v. 40, n. 3, p. 193-199, 2013. Disponível em:

<http://top.sagepub.com/content/40/3/193.full.pdf>. Acesso em: 26 de set. de 2019. doi: 10.1177/0098628313487461 